\title{
Use of Solid Waste (Foundry Slag) Mortar and Bamboo Reinforcement in Seismic Analysis for Single Storey Masonry Building
}

\author{
S. Ahmad $\cdot$ A. Husain $\cdot$ F. Ghani $\cdot$ M. N. Alam
}

Received: 6 August 2013/ Accepted: 27 March 2014/Published online: 12 April 2014

(C) The Institution of Engineers (India) 2014

\begin{abstract}
The conversion of large amount of solid waste (foundry slag) into alternate source of building material will contribute not only as a solution to growing waste problem, but also it will conserve the natural resources of other building material and thereby reduce the cost of construction. The present work makes an effort to safe and economic use of recycle mortar (1:6) as a supplementary material. Conventional and recycled twelve prisms were casted with varying percentage of solid waste (foundry slag) added $(0,10,20,30 \%)$ replacing cement by weight and tested under compression testing machine. As the replacement is increasing, the strength is decreasing. $10 \%$ replacement curve is very closed to $0 \%$ whereas $20 \%$ is farther and $30 \%$ is farthest. $20 \%$ replacement was chosen for dynamic testing as its strength is within permissible limit as per IS code. A 1:4 scale single storey brick model with half size brick was fabricated on shake table in the lab for dynamic testing using pure friction isolation system (coarse sand as friction material $\mu=0.34$ ). Pure friction isolation technique can be adopted economically in developing countries where low-rise building prevails due to their low cost. The superstructure was separated from the foundation at plinth level, so as to permit sliding of superstructure during severe earthquake. The observed values of acceleration and displacement responses compare fairly with the analytical values of the analytical model. It also concluded that $20 \%$ replacement of cement by solid
\end{abstract}

S. Ahmad $(\bowtie) \cdot$ F. Ghani $\cdot$ M. N. Alam

Department of Civil Engineering, Aligarh Muslim University,

Aligarh, India

e-mail: shakeel60in@yahoo.co.in

A. Husain

Department of Civil Engineering, Umme Qura University, Mekkah, Saudi Arabia waste (foundry slag) could be safely adopted without endangering the safety of the masonry structures under seismic load.To have an idea that how much energy is dissipated through this isolation, the same model with fixed base was tested and results were compared with the isolated free sliding model and it has been observed that more than $60 \%$ energy is dissipated through this pure friction isolation technique. In case of base isolation, no visible cracks were observed up to the table force of $4.25 \mathrm{kN}$ $(1,300 \mathrm{rpm})$, whereas for fixed base failure started at $800 \mathrm{rpm}$.To strengthen the fixed base model, bamboo reinforcement were used for economical point of view. Another model of same dimension with same mortar ratio was fabricated on the shake table with bamboo reinforcement as plinth band and lintel band. In addition another four round bamboo bars of $3 \mathrm{~mm}$ diameter were placed at each of the four corners of the model. The building model was tested and found very encouraging and surprising results. The model failure started at $1,600 \mathrm{rpm}$, which means that this model is surviving the double force in comparison with the non-bamboo reinforcement.

Keywords Masonry structure - Base isolation · Foundary slag $\cdot$ Bamboo reinforcement .

Earthquake engineering

\section{Introduction}

Masonry buildings have suffered the heaviest damage during earthquakes of moderate to severe intensities. Their vulnerability to damage results from several factors such as, their short period attracting large spectral acceleration, heavy weight along with low tensile and shear strength and poor workmanship. In-spite of the poor performance record 
of masonry structures during past earthquakes, they continue to be common option for building construction partly due to low cost. There has been a significant increase in the research activity aimed at improving earthquake resistance of masonry structures by providing reinforcement at critical sections of buildings. In-spite of all these measures, masonry building cracked during the medium and strong earthquakes. Such damage might be avoided only if it would be possible to find out some other way to dissipate the major portion of earthquake input energy. Most isolation system are too advanced and expensive for the application to masonry building in developing countries, where $80 \%$ of the houses are single or double storey and made of clay brick masonry. An alternative is to provide a base isolation system in which the isolation mechanism is purely sliding friction. Pure friction base isolation is introduced between the superstructure and the substructure to provide lateral flexibility and energy dissipation capacity.

In several major earthquake occurrences in developing countries like India and China, a beneficial behavior of low-rise buildings which could slide as rigid body over their foundations was observed during some past severe earthquakes, viz, the Dhubri earthquake in Assam in 1930, and in Bihar-Nepal earthquake in 1934. The damage study and the observation made in China, showed that those building in which the possibility of movement existed between the superstructure and the substructure, such structures suffered less damage than those buildings in which no such freedom of movement existed [1, 2]. A base isolation system has investigated in which the isolation mechanism is purely sliding friction [3, 4]. Such system utilizes pure friction to allow some parts of the structure to slide relative to the others. It differs from the other categories of sliding system due to the fact that in such a system there is no restoring force provided by any type of external horizontal springs. A simple mathematical model was introduced to complete the seismic response of masonry building with friction base isolation [3]. In this method, a new concept has been proposed for the construction of brick building in which a clear smoothened surface is created just above the damp proof course at plinth level without any mortar, and the superstructure simply rests at this level and is free to slide except for frictional resistance. The concept of friction seismic isolation system was further strengthened by the damage studies made after the Xintai (1966), Bohai (1969) and Tangshan (1976) earthquakes in which it was found that adobe buildings which were free to slide on their foundations (by accident) survived with little or no damage, whereas other buildings which were tied on their foundation collapsed [2]. Researchers have made experimental and theoretical studies to incorporate such a system in masonry buildings economically to achieve a collapse free, if not a damage free performance during the earthquakes. Further studies have also been made with encouraging results $[4,5]$. Masonry building with demolished waste mortar under static and dynamic load condition with pure friction base isolation has been tested [6].

In recent years recycling of demolished waste is in progress to conserve the natural resources. We know conservation of natural resources and preservation of environment is the essence of any development. Rapid growth in population and urbanization are pushing the growth in construction, especially in the developing countries and old buildings are being demolished to replace with new one. Construction and demolished waste leads to two basic problems. On the one hand there is an urgent need to fruitfully use the construction debris, which is often simply thrown away or used as a filling material, without considering the ensuing environmental problems. On the other hand, the construction industry is faced with the nonavailability of good quality construction materials within reasonable distances. Thus the factors such as environment economy, shortage of land disposal and the shortage of good quality of raw materials for construction make it imperative that waste should be suitably recycled. It may be pointed out that Asia alone produces about 760 million tones of demolished waste every year. Recycling of construction and demolished waste was first carried out after the Second World War in Germany to tackle the problem of disposing large amounts of demolition waste caused by the war and simultaneously generate raw material for reconstruction. Considerable research has been carried out in USA, Japan, UK, France, Germany and Denmark etc. for recycling concrete, stone, and brick masonry, bituminous and other constituents of waste from construction industry. Previous investigations were mainly engaged in the processing of demolished concrete, the mixture design, and the physical and mechanical properties as well as the durability improvements. Most of the achievements have been extensively reviewed and summarized [7-9]. Recent works on recycled aggregate concrete and recycled materials and demolished waste have been reported in the literatures [10-15]. A detail work has been done on Variation in strength of concrete on addition of demolished waste [16]. The masonry building with demolished waste mortar under static and dynamic load condition with pure friction base isolation has also been tested [6].

Very little work has been reported on seismic performance of masonry buildings with recycled mortar with bamboo reinforcement. Keeping in view, pure friction base isolated masonry building with foundry sludge waste mortar was tested for its dynamic performance. To strengthen it bamboo reinforcement at lintel level and at all the four corners were also placed and tested under dynamic condition to see its performance. 
Table 1 Chemical composition of foundry slag

\begin{tabular}{lcc}
\hline Chemical composition & Specimen (KR211) & Specimen (KR222) \\
\hline Silicon dioxide $\left(\mathrm{SiO}_{2}\right)$ & 45.59 & 45.26 \\
Aluminium oxide $\left(\mathrm{Al}_{2} \mathrm{O}_{3}\right)$ & 13.76 & 15.68 \\
Potassium oxide $\left(\mathrm{K}_{2} \mathrm{O}\right)$ & 0.36 & 0.36 \\
Sodium oxide $\left(\mathrm{Na}_{2} \mathrm{O}\right)$ & 0.45 & 0.49 \\
Magnesium oxide $(\mathrm{MgO})$ & 0.66 & 0.64 \\
Manganese oxide $(\mathrm{MnO})$ & 5.52 & 5.67 \\
Calcium oxide $(\mathrm{CaO})$ & 1.89 & 1.73 \\
Ferric oxide $\left(\mathrm{Fe}_{2} \mathrm{O}_{3}\right)$ & 24.01 & 24.51 \\
Phosphorus oxide $\left(\mathrm{P}_{2} \mathrm{O}_{5}\right)$ & 0.07 & 0.07 \\
Titanium oxide & 1.57 & 1.58 \\
\hline
\end{tabular}

\section{Experimental Study}

\section{Casting and testing of prisms}

The source of foundry slag (FG) mortar for casting the prism $(115 \times 210 \times 210 \mathrm{~mm})$ was a part of iron industry (Agrawal Farro Metallic) which is situated near by Aligarh airport and is about $14 \mathrm{~km}$ from Aligarh city. The waste in lumps was transported crushed in the Lab and sieved through a $90 \mathrm{~mm}$ IS sieve in order to get the same fineness as that of cement. The chemical analysis was conducted at Wadia Institute of Himalayan Geology Lab in Dehradun, the composition of the slag is reported in Table 1 . It is observed that the slag mainly comprises of oxides of Silica, Iron and Alumina. The two samples analyzed show that the silica content dominates.

The petro graphic analysis of slag was also carried out by making thin sections and using petro logical microscope. It shows pores of varying sizes with almost circular shapes. The slag groundmass is dense and compact and shows perlitic cracks which are the result of heating it has undergone during the process of smelting.

The foundry slag waste exhibits pozzolanic properties, which led to its use as a constituent of mortar. A pozzolanic material is defined as a "Siliceous or siliceous and aluminous material which possess little or no cementitious value but in finely divided form and in presence of moisture chemically react with calcium hydroxide at ordinary temperature to form compound possessing cementitious properties". The foundry slag waste was grinded and passed through 90 micron sieve. Half size bricks $(115 \times 56 \times 35 \mathrm{~mm})$ used in casting the prisms and house building models for dynamic testing have been manufactured in the Department itself just to maintain the uniformity and quality of bricks. As per BIS specifications the standard tests have been performed on bricks. The prism under compression test has been shown in Fig. 1. The shape and texture is smooth with rectangular sharp corners and the bricks give a metallic sound when struck. The cement used in the experimental work was Ordinary Portland Cement of grade 43 conforming to BIS 8112:1989 specifications [17]. Normal consistency was $30 \%$; initial setting time was $40 \mathrm{~min}$. Compressive and tensile strength (7 days) was 31.67 MPa and 2.55 MPa, respectively. The Ganga River sand was used as the inert material for the preparation of the mortar, in which $20 \%$ Badarpur sand (coarse sand) was mixed to satisfy the requirement as per BIS 2116:1980 specifications [18]. The fineness modulus of the sand was 3.6. Twelve prisms were casted using 1:6 cement sand mortar. FG waste was added partially replacing cement $(0$, 10,20 and $30 \%$ ) to obtain recycled mortar. Since brick masonry normally requires a high workable mortar, the water was mixed in the mortar so as to achieve optimum workability. Bricks were soaked in water completely before laying. Each prism was prepared with six courses of bricks, so as to make slenderness ratio equal to two. The joints in masonry were filled with care for a constant thickness of mortar of $4.5 \mathrm{~mm}$. The sides of the prism were regularly checked by plumb. All prisms were casted by the same mason for uniformity in all respects. The prisms were kept under wet gunny bags and cured regularly for 28 days. All specimens were air dried for $24 \mathrm{~h}$ before testing. The prisms were tested for crushing strength in compression by Universal testing machine. Before the test DEMAC points were fixed on the prisms by araldite at a distance equal to the gauge length $(10 \mathrm{~cm})$ of the gauge used. The prisms were then tested in compression testing machine. The prisms were placed between two $3 \mathrm{~mm}$ thick plywood sheets. The load was then applied at a constant rate of $0.7 \mathrm{~N} / \mathrm{mm}^{2} / \mathrm{min}$. At regular interval loading dial gauge readings were noted. Initially the dial gauge reading was set to zero. The stressstrain curve for different prisms is shown in Fig 2.

A rectangular masonry building model of dimension $1020 \times 970 \times 720 \mathrm{~mm}$ with wall thickness $56 \mathrm{~mm}$ on a geometric scale of 1:4 was constructed on a channel section ISLC $75(75 \times 40 \times 5 \mathrm{~mm})$ which is fixed with the shake table. A smoothened surface was created at the plinth level to achieve discontinuity; a frictional material (coarse sand) was placed at this surface. The coefficient of friction of this material was determined in the laboratory and found to be 0.36 whereas in literature the coefficient of friction for coarse sand is reported as 0.35 [3. From Fig. 2 it is observed that as replacement of conventional cement with recycled material is increasing, the strength of masonry prism is decreasing. $10 \%$ replacement was very close to $0 \%$ replacement strength. $30 \%$ replacement gives very low strength in static and so $20 \%$ replacement has been adopted in seismic model testing to see its performance even on low strength. Therefore, the model was constructed in 1:6 cement sand mortar with $20 \%$ replacement. Same half size bricks were used for model preparation. The bricks were cured in a 


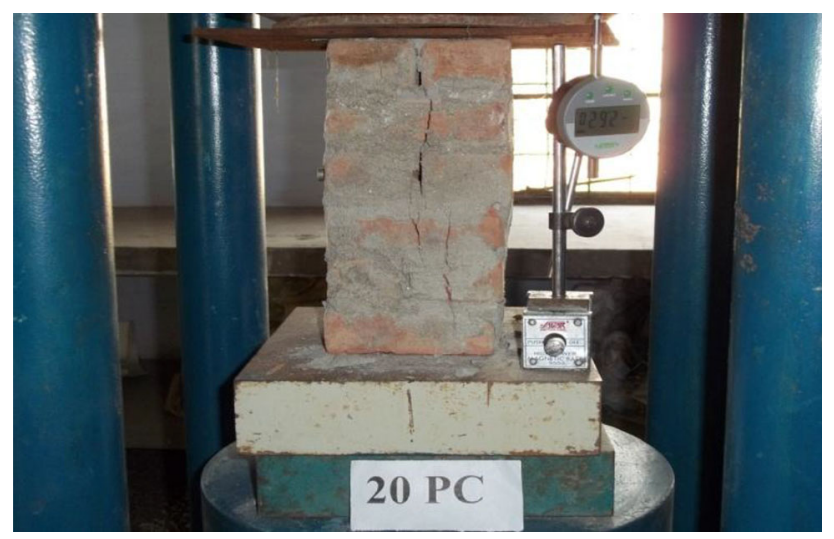

Fig. 1 Masonry prism under compression testing machine

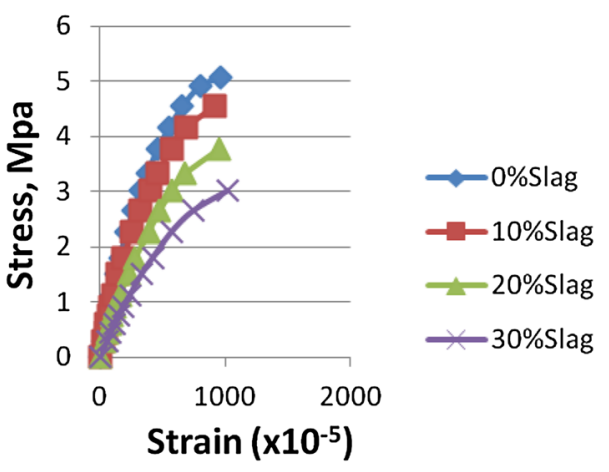

Fig. 2 Stress strain curve for different percentage of FG waste prisms

tank full of water for $24 \mathrm{~h}$ before constructing the model whereas the building model was cured for 28 days. A wooden door of dimension $215 \times 255 \mathrm{~mm}$ was provided in one shear wall and the other of size $(230 \times 260 \mathrm{~mm})$ in opposite shear wall. Thickness of slab was $38 \mathrm{~mm}$. The model was tested for base with pure friction free sliding and fixed base. Model with pure friction isolation system has been shown in Fig 3. As per BIS 1893:2002 natural time period of the model was found to be $0.064 \mathrm{~s}$ and mass ratio as 2.60 [19]. A mechanical oscillator and a motor were below the unidirectional shake table to create sinusoidal response. The mechanical oscillator consists of two shafts rotating in opposite direction. Each shaft carries a set of eccentric masses, which generate force in a direction normal to the line joining the shafts. One of the shaft assemblies is constructed in such a way that its eccentric mass can be rotated to change its position relative to the masses on the other shaft to change the degree of eccentricity. A knob is provided outside the oscillator at the end of one shaft assembly to change the degree of eccentricity. For every revolution of this knob, the eccentricity changes by 4.1. A speed control unit is also provided to regulate the rpm of rotating masses. The generation of force by oscillator depends upon eccentricity and rpm of rotating masses. Force at different speeds and eccentricities have been shown in Fig. 4. In order to assure

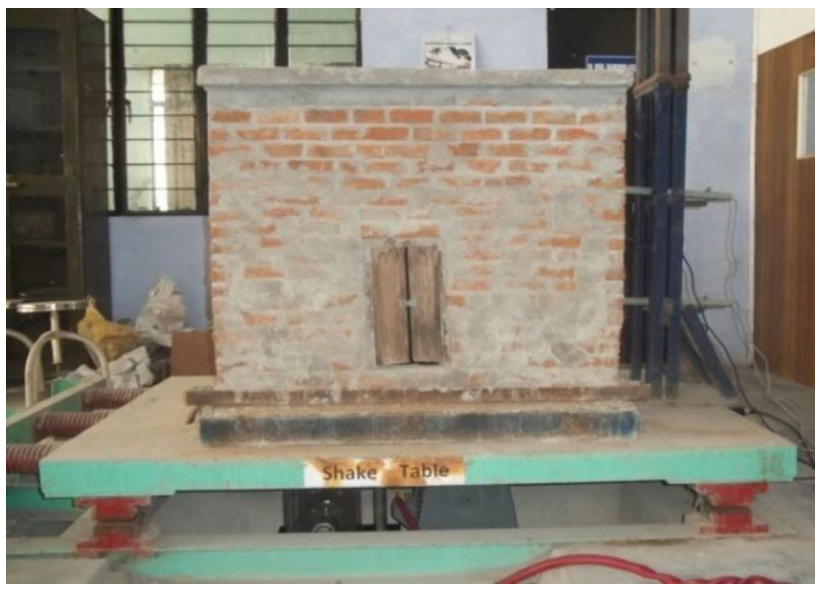

Fig. 3 Pure friction (coarse sand) masonry model with LVDT and Accelerometers

the degree of accuracy, a data logger with 48 channels as well as in-built software (conversion to volts) for acquiring dynamic responses (acceleration and displacement) were used. The limit to acquire acceleration is -3 to $+3 \mathrm{~g}$ and displacement -20 to $+20 \mathrm{~mm}$. The data can be acquired in digital as well as in graphical form. The digital data can be directly transferred to Microsoft Excel for further processing of acquired data. Out of the three accelerometers, one was placed at the base of the shake table for table acceleration, which will be treated as ground acceleration in prototype where as the other two were mounted at the top and base of the model for their responses (Fig 3). The model was tested for different rpm, which is connected to table force. The data were acquired and analysed for free sliding (Fig. 3) as well as fixed base system and peak model responses were plotted against table forces. The table acceleration acquired were used for mathematical model analysis to compute top and base responses of the model and finally compared with the observed values.

To strengthen the fixed base model bamboo reinforcement was used at the corners and at the plinth and lintel level (Fig. 5). The bamboo reinforcement used at the corner and is of round shape (Fig. 5) which is inserted in the model bricks to make a hole. To see bamboo degradation effect, the four specimens were put in four different jars with coal tar, water, lethal and grease for three months. In lethal the bamboo degradation effect was found negligible then coal tar. Therefore for construction with bamboo reinforcement lethal may be wrapped around the bamboo specimen for protecting it from degradation.

\section{Mathematical Model}

It is assumed that a layer of suitable material with known coefficient of friction is laid between contact surfaces of 


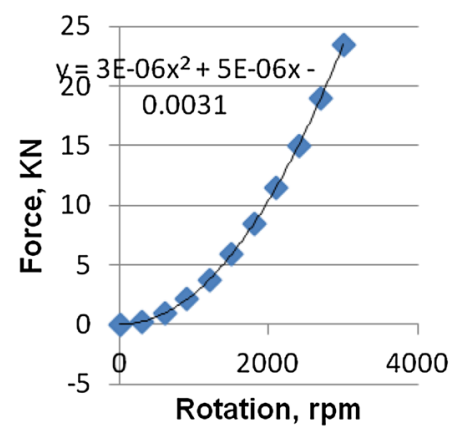

Fig. 4 Table force against rotation

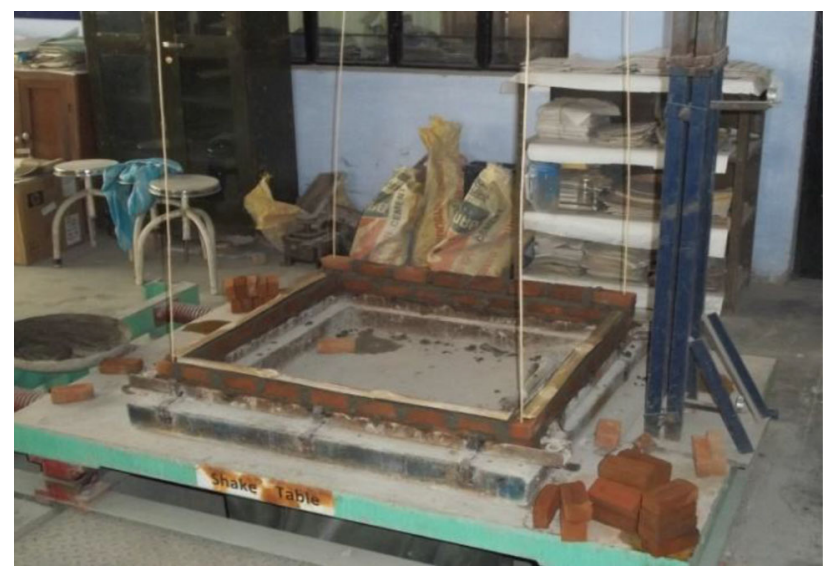

Fig. 5 Masonry model with Bamboo reinforcement at plinth and at corners

super structure and the smoothened surface at plinth level. The sliding-type building is idealized as discrete mass model with two degrees of freedom for computing its earthquake response. The spring action in the system assumed to be provided by the shear walls, i.e., those resisting shear forces parallel to the direction of earthquake shock. Internal damping is represented by a dashpot that is parallel with the spring. The mass of the roof slab and of one-half the height of the wall is lumped at the roof level; the other half of the height of the wall is lumped at the level of plinth. The lower mass is assumed to rest on a plane with dry frictional damping to permit sliding of the system (Fig 6).There are three different phases in the complete motion history of the sliding system due to friction at its base. The equations of motion are derived:

\section{Phase-I}

Initially, bottom mass moves with the base so long as sliding force does not overcome the frictional resistance. So the building behaves as a single degree of freedom system and therefore equation of motion is

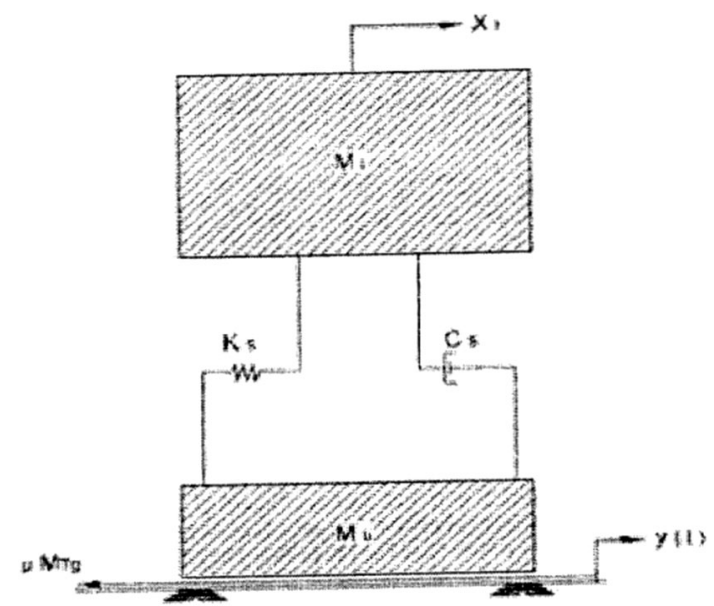

Fig. 6 Mathemetical model for two degree freedom system

$M_{t} \ddot{x}_{t}+C_{s}\left(\dot{Z}_{t}-\dot{Z}_{b}\right)+K_{s}\left(Z_{t}-Z_{b}\right)=0$

or

$\ddot{Z}_{t}+2 \omega \xi\left(\dot{Z}_{t}-\dot{Z}_{b}\right)+\omega^{2}\left(Z_{t}-Z_{h}\right)=-\ddot{y}(t)$

where, $\mathrm{C}_{\mathrm{s}}=$ coefficient of the viscous damper; $\mathrm{K}_{\mathrm{s}}=$ spring constant; $\mathrm{M}_{\mathrm{t}}=$ top mass; $\mathrm{M}_{\mathrm{b}}=$ bottom mass; $\ddot{X}_{t}, \ddot{Z}_{t}=$ absolute and relative acceleration of the top mass respectively; $\ddot{y}(t)=$ ground acceleration at time $\mathrm{t} ; \mathrm{Z}_{\mathrm{b}}, \mathrm{Z}_{\mathrm{t}}=$ lateral relative displacement of masses $M_{b}$ and $M_{t}$ respectively; $\dot{Z}_{b}, \dot{Z}_{t}=$ relative velocity of masses $\mathrm{M}_{\mathrm{b}}$ and $\mathrm{M}_{\mathrm{t}}$, respectively; $\omega=$ natural frequency and $\xi=$ fraction of critical damping.

\section{Phase II}

The sliding of the bottom mass begins when the sliding force overcomes the frictional resistance at the plinth level. The force to cause sliding $\mathrm{S}_{f}$ is given by

$S_{f}=C_{s}\left(\dot{Z}_{t}-\dot{Z}_{b}\right)+K_{s}\left(Z_{t}-Z_{b}\right)-M_{b} \ddot{X}_{b}$

Sliding of bottom mass occurs is

$\left|\mathrm{S}_{f}\right|>\mu \mathrm{M}_{\mathrm{T}} \mathrm{g}$

when, $\mathrm{g}=$ acceleration due to gravity; total mass $\left(\mathrm{M}_{\mathrm{T}}\right)=\mathrm{M}_{\mathrm{b}}+\mathrm{M}_{\mathrm{t}}$ and $\mu=$ Coefficient of friction.

The building now acts as a two degree of freedom system for which the equation of motion can be written in a simplified form as:

$\ddot{Z}_{b}-2 \omega \xi \theta\left(\dot{Z}_{t}-\dot{Z}_{b}\right)-\omega^{2} \theta\left(Z_{t}-Z_{b}\right)+F=-\ddot{y}(t)$

$\ddot{Z}_{b}-2 \omega \xi\left(\dot{Z}_{t}-\dot{Z}_{b}\right)-\omega^{2}\left(Z_{t}-Z_{b}\right)=-\ddot{y}(t)$

where, $\mathrm{F}=\mu g(1+\theta) \operatorname{sign}\left(\dot{\mathrm{Z}}_{\mathrm{b}}\right)$;

$\ddot{Z}_{b}=$ relative acceleration of bottom mass; $\operatorname{sign}\left(\dot{Z}_{b}\right)=+1$ if $\left(\dot{Z}_{b}\right)$ is positive; $\operatorname{sign}\left(\dot{Z}_{b}\right)=-1$ if $\left(\dot{Z}_{b}\right)$ is negative and $\theta=\frac{M_{1}}{M_{b}}=$ mass ratio. 


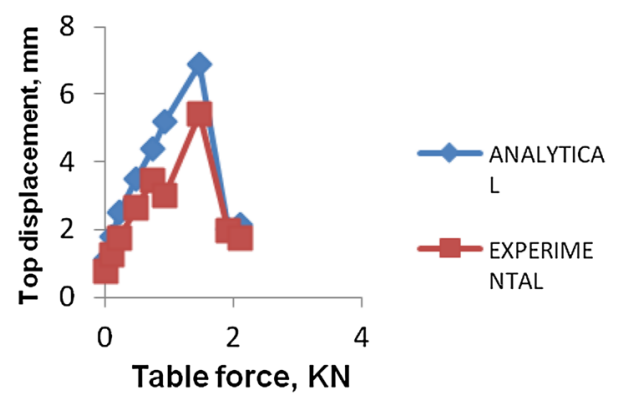

Fig. 7 Table force against top displacement (free sliding model system)

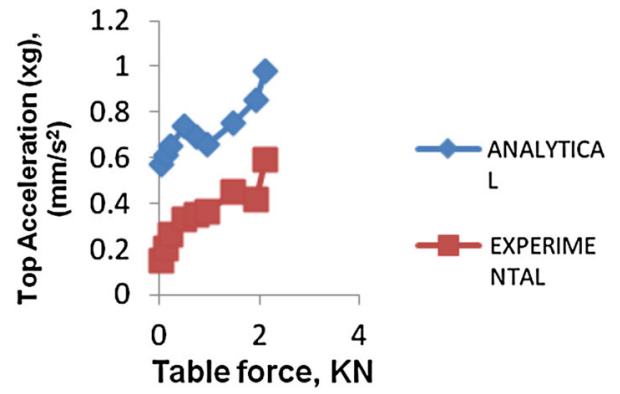

Fig. 8 Table force against top acceleration (free sliding model system)

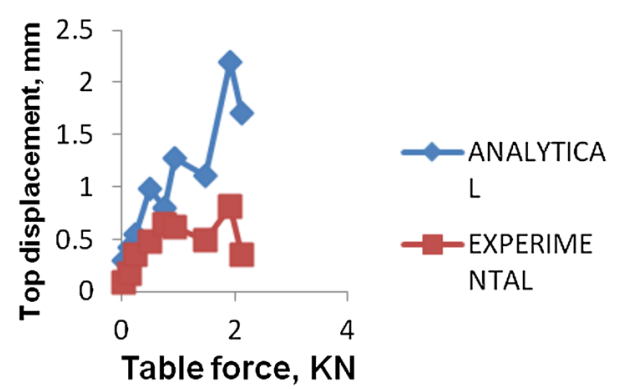

Fig. 9 Table force against top displacement (fixed base system)

\section{Phase-III}

At any instant of time during motion of the systems if

$$
\left|\mathrm{S}_{f}\right|<\mu \mathrm{M}_{\mathrm{t}} \mathrm{g}
$$

Then the sliding of the bottom mass is stopped but the top mass continues to vibrate. Therefore, again the system becomes a single degree of freedom system and Eq. 2 would govern its motion. Throughout the time history of the ground shaking, the bottom mass of the system either stops or continues to the condition enumerated earlier.

\section{Results and Discussion}

After testing the prisms, it has been observed that on partial replacement of cement with 10,20 and $30 \%$ FG waste, the

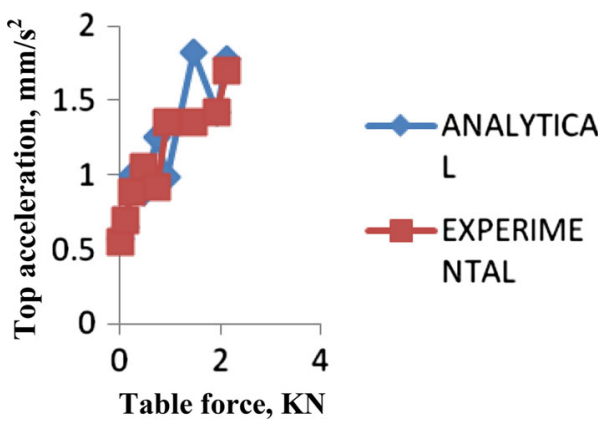

Fig. 10 Table force against top acceleration (fixed base system)

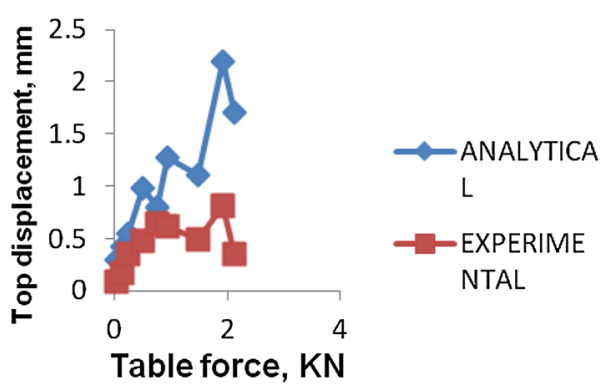

Fig. 11 Table force against top displacement (fixed base bamboo reinforced model system)

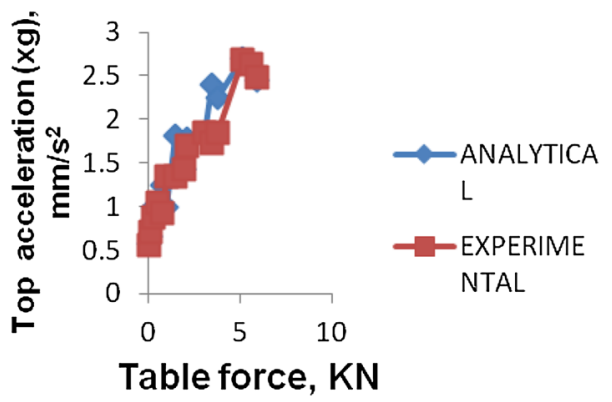

Fig. 12 Table force against top acceleration (fixed base bamboo reinforced model system)

decrement in average compressive strength with respect to $0 \% \mathrm{FGW}$ was found to be 3,20 and $40 \%$, respectively (Fig. 2).Model with pure friction base isolated material i.e. dry coarse sand (coefficient of friction $\mu=0.36$ ) was tested on unidirectional shake table. Top acceleration, bottom acceleration, top displacement, bottom displacement and table acceleration were recorded changing the force on the shake table with changing the motor speed. The peak values from recorded time history of top and bottom acceleration as well as top and bottom displacement were taken for plotting graphs. The time histories of table acceleration at different rpm of the motor were used in the mathematical model to calculate the top and bottom acceleration as well as top and bottom displacement of the model for validation of the analytical model. The analytical and experimental, top displacements and accelerations 


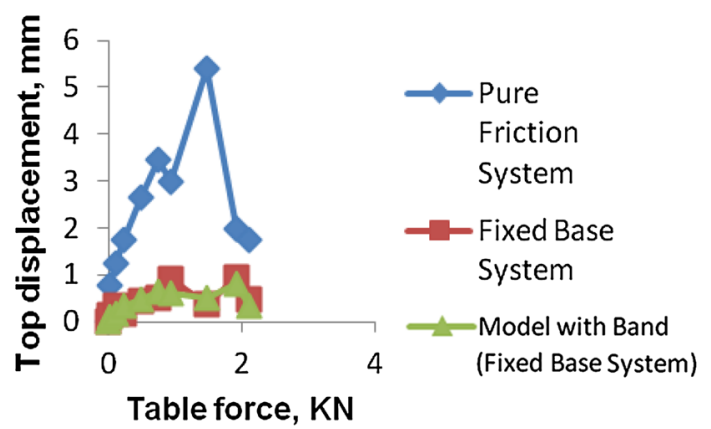

Fig. 13 Table force against top displacement for all the three systems

have been shown in Figs 7, 8 respectively which are fairly comparable. To have an idea that how much energy is dissipated through this isolation, the same model with fixed base was tested and results were compared with the base isolation results (Figs 9, 10). From these graphs it is clear that more than $60 \%$ energy is dissipated when the sliding of model took place. In case of base isolation, no visible cracks were observed up to a table force of $4.25 \mathrm{kN}$ $(1,300 \mathrm{rpm})$, whereas for fixed base bond failure was observed at $2.11 \mathrm{kN}$ (900 rpm).

In the case of model constructed with bamboo band and corner reinforcement was also tested and found very encouraging and surprising results. The model failure stated at $1,600 \mathrm{rpm}$. This means this model is surviving the double force in comparison with without bamboo reinforcement. The top displacements and accelerations have been shown in Figs 11, 12. The table force v/s top displacements in all the above three conditions have been shown in Fig. 13.

\section{Conclusion}

On the basis of experimental and analytical results following conclusions are drawn:

- A $20 \%$ replacement of cement by foundry slag can be safely adopted without endangering the safety of structure providing pure friction isolation system.

- No visible cracks have been observed when sliding of model took place.

- Fixed base model failed in shear at $900 \mathrm{rpm}$ whereas model with pure friction base isolation at the same rpm didn't.

- Model constructed with bamboo band failed in shear at $1,600 \mathrm{rpm}$. This means this model is surviving the almost double force in comparison with without bamboo reinforcement.
- Good agreement between experimental and analytical model results.

- $60 \%$ energy dissipated when the sliding of model took place.

- Use of foundry slag in masonry reduced the cost by 10 percent.

\section{References}

1. E.R. Gee, "Dhubri earthquake of 1930", Memories of geological survey of India. India LXV, 1-106 (1934)

2. Li, Li. (1984) Base Isolation Measures for a Seismic in China," Eight World Conference on Earthquake Engineering, vol. IV (San Francisco, California, 1984) pp. 791-798

3. Arya A.S., Chandra B. and Qamruddin M. A new building system for improved earthquake performance. Proceedings of the 6th symposium on earthquake engineering, vol. 1 University of Roorkee, India, 1978 pp. 499-504

4. M. Qamaruddin, A.S. Arya, B. Chandra, Seismic response of brick buildings with sliding substructures. Eng. Mech. ASCE 112(1981), 558-572 (1981)

5. N. Mostaghal, J. Tanbaknchi, Response of sliding structures to earthquake support motion. Earthq. Eng. Struct. Dyn. 11, 729-748 (1983)

6. S. Ahmad, F. Ghani, M.A. Raghib, Seismic Friction Base Isolation Performance using Demolished Waste in Masonry Housing. Constr. Build. Mater. 23, 146-152 (2008)

7. P.J. Nixon, Recycled concrete as an aggregate for construction-a review. Mater. Struct. 11, 371-378 (1978)

8. Hansen TC, Recycling of Demolished Concrete and Masonry (E \& FNSPON, London, 1992)

9. ACI committee 555. Removal and reuse of hardened concrete. ACI Mater. J. 002(99), 300-25

10. M. Arm, Self-cementing properties of crushed demolished concrete in unbound layers: results from triaxial tests and field tests. Waste Manag 21(3), 235-239 (2001)

11. C.S. Poon, S.C. Kou, L. Lam, Use of recycled aggregates in molded concrete bricks and blocks. Constr. Build. Mater. 16(5), 281-289 (2002)

12. V. Corinaldesi, M. Giuggiolini, G. Moriconi, Use of rubble frombuilding demolition mortars. Waste Manag 22(8), 893-900 (2002)

13. J.M. Khatib, Properties of concrete incorporating fine recycled fine aggregate. Cem. Concr. Res. 35(4), 763-769 (2005)

14. V.W. Tam, C.M. Tam, A-review on the viable technology for construction waste recycling. Resour. Conserv. Recy. 47(3), 209-221 (2006)

15. J. Xiao, Y. Sun, H. Falkner, Seismic response of frame structures with recycled aggregate concrete. Eng. Struct. 28, 1-8 (2006)

16. A. Masood, T. Ahmad, F. Ghani, D.S. Rawat, Variation in strength of concrete on addition of demolished waste. Indian Concr. J. 72(8), 395-399 (1998)

17. BIS, 8112 Specifications for 43 grade ordinary Portland cement (BIS, New Delhi, 1989)

18. BIS, 2116 Specification for sand for masonry mortars (BIS, New Delhi, 1980)

19. BIS, Criteria for earthquake resistant design of structures (BIS, New Delhi, 1893). 2002 